\title{
Asylum Seekers and the Co-production of Public Services: Understanding the Implications for Social Inclusion and Citizenship
}

\author{
KIRSTY STROKOSCH* AND STEPHEN P. OSBORNE** \\ * Centre for Service Excellence, University of Edinburgh Business School, 29 Buccleuch \\ Place, Edinburgh, EH8 9JS \\ email: kirstystrokosch@hotmail.com \\ ** Centre for Service Excellence, University of Edinburgh Business School, 29 Buccleuch \\ Place, Edinburgh, EH8 9JS \\ email: Stephen.Osborne@ed.ac.uk
}

\section{Introduction}

This paper presents an empirical study of asylum seekers in Glasgow and their capacity to co-produce the public services they use. It is divided into three parts. The first briefly examines the theory of co-production, revisiting a conceptual framework for co-production developed through the integration of the public administration and services management literatures (Osborne and Strokosch, 2013). Second, the paper examines the capacity of asylum seekers in Scotland to co-produce, considering their position as a marginalised group in society which significantly challenges many of the assertions about the nature of coproduction. Finally, the paper discusses the implications of this new evidence for our understanding of the links between public services consumption and citizenship, asking two fundamental questions: can asylum seekers, as noncitizens, co-produce the public services they receive and, if so, what forms does co-production take; and what are the implications of this for social inclusion and citizenship?

\section{Conceptualising co-production}

Previous work by these authors has explored how the public administration and services management literatures might be integrated to produce a more holistic understanding and conceptualisation of co-production (Osborne and Strokosch, 2013). It argued that the services management literature offered a better starting point for theorising about the actuality of the co-production of public services and its management than did the public administration literature because of its greater clarity about the service delivery process (e.g. Norman, 1991; Gronroos, 
2007; Vargo and Lusch, 2008). The public administration literature by contrast offers valuable insight into how co-production can be extended through various participative mechanisms to plan service development (e.g. Ostrom, 1972; Parks et al., 1981; Brandsen and Pestoff, 2006; Bovaird, 2007; Alford, 2009). Taken together, these two literatures provide a more comprehensive view of the co-production of public services, suggesting that different levels of co-production can be achieved. It posits that there are three potential modes of co-production for the individual service user - consumer, participative and enhanced.

\section{Consumer co-production}

In this first mode, co-production is intrinsic to service production given the inseparability of production and consumption for services which occur simultaneously in time and space (Johnston and Clark, 2008; Vargo and Lusch, 2008). Service consumption is crucial to the process of service production and as such, consumer co-production forms the service users' contribution at the most basic level. It is involuntary and unavoidable on the part of both the service user and service provider. In this context positive engagement with such intrinsic co-production is a core element of the effective management of public services on a day-to-day basis.

\section{Participative co-production}

In the second mode, co-production is extended beyond consumption into the planning, development and evaluation of existing forms of public service. Service users can take a more active role here through either citizen participation or consumer mechanisms in order to develop and improve existing forms of public services. However, this involvement is at the behest and control of the service provider.

\section{Enhanced co-production}

The final mode suggests a more fundamental role for public service users where they can contribute their expertise to co-design and co-create service innovations that result in new forms of public services. The role of the service user is embedded into this innovation process, drawing on their knowledge to create new forms of public services as opposed to focusing on the service encounter alone (Kristensson et al., 2008; Ordanini and Pasini, 2008). This is facilitated by an active dialogue between public service professionals and public service users that combines the 'expert' professional knowledge of the service professionals with the latent 'sticky' knowledge of service users (von Hippel, 1994).

\section{Asylum seekers: marginalised and non-citizens}

Asylum is currently a worldwide concern with the movement of millions of people from the Middle East and Africa into Europe. This study focuses specifically on asylum seekers and the social welfare services they receive in Glasgow. The case of 
asylum seekers is particularly interesting given their marginal position in society (Bloch, 2000).

\section{Citizenship: a status and/or a practice?}

Since the mid-1980s, successive UK governments have taken increasingly strict measures to deter asylum seekers and/or contain them within their home countries (e.g. through visa requirements). According to Cemlyn and Briskman (2003), a key strand of this deterrence policy has been the dismantling of social rights for asylum seekers, thereby detaching them from any provisions associated with citizenship. Interestingly, Choules (2006) describes three fundamental elements of citizenship: membership of the political community; membership of a community of shared character; and membership of a welfare state.

Asylum seekers sit in a contentious position, having exercised their legal right under the Geneva Convention (1951) to apply for asylum, but remaining noncitizens while they await the outcome of their case. As such, they are prevented from engaging in policy-making processes (Haikio, 2010). Furthermore, asylum seekers are regulated and constrained by strict immigration laws, which are rooted within and built upon 'policies of deterrence' (Williams, 2006). The legislation has also built a stratified system of social rights which limits asylum seekers' access to public services and singles them out as a visibly in-need group distinct from mainstream society (Sales, 2002). This inequality is deepened both through notions of citizenship which have been constructed as a means of excluding outsiders (Cemlyn and Briskman, 2003; Choules, 2006) and through the 'demonisation' of asylum seekers by politicians and the media (Cemlyn and Briskman, 2003). Their lives are regulated and constrained by immigration laws and they are forbidden to work for remuneration which potentially impedes their capacity to integrate into society. Taken together, this effectively precludes them from membership of Choules' first category of citizenship - though not necessarily from the subsequent two.

Although they are not party to a political community, as a distinct group of asylum seekers, with all the political and economic consequences that result, they arguably have membership of a smaller community of shared character Choules' second category of membership required for citizenship. Furthermore, asylum seekers are positioned as public service users, which suggests that they also fulfil the third category of Choules' elements of citizenship: membership of a welfare state.

Importantly, Haikio (2010) argues that most empirical work on public management reforms has failed to give adequate attention to such issues and linkages to citizenship, despite public management and public service delivery being 'an integral part of social practices and norms that define citizenship, relations of power and people's influence over political decisions' (Haikio, 2010: $367)$. 
This is at the heart of the issue that we explore here. Asylum seekers' role as public service users highlights the contradiction of their lack of citizenship status because they are not members of the polity with a potential for citizenship through their shared community and the role they can play in the welfare state through the co-production of services. Although they cannot participate on an economic and political level, there are opportunities for them to co-produce public services and therefore contribute to public service production. Their role as public service users is therefore crucial.

Interestingly, Lister (2003) differentiates between citizenship as a status and a practice. Status is about being a citizen, while practice is about acting as a citizen. Asylum seekers certainly do not have the legal status of citizens, but perhaps coproduction provides a route for them to act or practise citizenship. Consequently we question whether the co-production of public services offers a route towards citizenship in practice and what the implications of this are for the citizenship debate. This is the contribution of this paper to the debate.

\section{Asylum seekers in Scotland: an empirical study Methods}

The research reported here is part of a broader study that examined the extent to which the public management reform agenda in Scotland was enabling asylum seeker involvement in the provision of social welfare services. This paper uses the evidence from social policy interviews and a cross-sectional case study of Glasgow in order to explore the impact of co-production upon the citizenship and social inclusion of asylum seekers.

In-depth policy interviews were conducted with seven key national and citywide organisations, which were selected through the use of a purposive sampling technique. The respondents are displayed in Figure 1 below.

\begin{tabular}{|c|}
\hline POLICY RESPONDENTS \\
\hline Scottish Government Policy 1 \\
Scottish Government Policy 2 \\
Scottish Government Policy 3 \\
UK Government Agency \\
Charity Manager \\
Accommodation Provider Strategic Manager \\
Community Planning Partnership Manager \\
\hline
\end{tabular}

Figure 1. Policy Respondents 
The Glasgow case study was split into six sub-units, each of which is described in Figure 2 below, along with the methods used to gather the data in each. Eleven interviews with service managers and front-line staff were conducted, as well as ten interviews with asylum seekers who were utilising existing public services in Glasgow. Eight non-participative observations were also carried out to explore the process of public service delivery and to generate a deeper understanding of the interactions between public service organisations (PSOs) and asylum seekers.

\begin{tabular}{|c|c|c|}
\hline SUB-UNITS & CASE DESCRIPTION & METHODS USED \\
\hline Church A & $\begin{array}{l}\text { Small community } \\
\text { organisation providing } \\
\text { services to asylum seekers } \\
\text { (AS) }\end{array}$ & $\begin{array}{ll}\text { - } & \text { Service manager interview } \\
\text { - } & \text { Observation }\end{array}$ \\
\hline Church B & $\begin{array}{l}\text { Small community } \\
\text { organisation providing } \\
\text { services to AS }\end{array}$ & $\begin{array}{ll}\text { - } & \text { Service manager interview } \\
\text { - } & \text { Asylum seeker interview } \\
\text { - } & \text { Observation }\end{array}$ \\
\hline Accommodation provider & $\begin{array}{l}\text { PSO that houses asylum } \\
\text { seekers in Glasgow under a } \\
\text { contract with UKBA }\end{array}$ & $\begin{array}{ll}\text { - } & \text { Service manager interview } \\
\text { - } & \text { Strategic Manager interview } \\
\text { - } & \text { Government Agency } \\
& \text { interview } \\
\text { - } & \text { Observation }\end{array}$ \\
\hline Humanitarian Organisation & $\begin{array}{l}\text { National organisation that } \\
\text { provides services to AS }\end{array}$ & $\begin{array}{ll}\text { - } & \text { Service manager interview } \\
\text { - } & \text { Front-line staff interview }\end{array}$ \\
\hline Development Organisation & $\begin{array}{l}\text { City-wide organisation that } \\
\text { offers services to AS }\end{array}$ & $\begin{array}{l}\text { - } \\
\text { - } \\
\text { Front-line staff interview } \\
\text { (duo) } \\
\text { - } \\
\begin{array}{l}\text { Asylum seeker interview } \\
\text { (duo) }\end{array} \\
\text { - Observation }\end{array}$ \\
\hline Young Persons' Group & $\begin{array}{l}\text { Group which provides } \\
\text { services to asylum seekers in } \\
\text { care }\end{array}$ & $\begin{array}{l}\text { - } \text { Service manager interview } \\
\text { - } \text { AS group interview } \\
\text { - } \text { Observation }\end{array}$ \\
\hline
\end{tabular}

Figure 2. Case study sub-units and methods

This paper uses this data to explore the two research questions outlined below:

- RQ1: can asylum seekers, as non-citizens, co-produce the public services they receive and, if so, how do they co-produce these services?; and

- RQ2: what are the implications of co-production for social inclusion and as a potential route to citizenship?

\section{Asylum Seeker Policy: the Scottish context}

The Immigration and Asylum Act 1999 (amended in 2002 by the Nationality, Immigration and Asylum Act) introduced, for the first time, a nationally coordinated approach to asylum seeker resettlement and support. Key to the 
legislation was the introduction of 'no choice' dispersal which attempted to lessen strain on London and the South East. Contracts were entered into between the UK Borders Agency (UKBA) and housing providers from throughout the UK. Glasgow City Council was the only local authority in Scotland to enter into such an agreement and, at the time of this study, the YMCA (renamed Y People since this research was conducted) and the for-profit organisation Angel also provided asylum seeker accommodation in the city.

Although responsibilities for immigration policy lie clearly with the UK Government, there are differences in Scotland compared to England, in terms of demography, political climate and integration policy. In Scotland there was a concern about the population decline, coupled with low fertility and an ageing population (Wren, 2007) and asylum seekers were therefore viewed as a means of potentially filling the resulting skills gap (Sim and Bowes, 2007). Research conducted by Lewis (2006) also found a greater tolerance to asylum seekers in Scotland than England, with the Scottish media latterly becoming less suspicious of asylum seekers (see, for example, Johnston, 2003; Anon, 2005; Anon, 2001).

The Scottish Government is responsible for the devolved policy agenda and the provision of public services to asylum seekers, including access to healthcare, education for children and social care needs (Wren, 2007). Through public service provision, the Scottish Government promotes the integration of asylum seekers into Scottish society, through initiatives such as English language classes and translation assistance. The process of integration begins during the application process rather than after refugee status is awarded, as is the approach in England (Wren, 2007).

\section{Empirical findings and discussion Policy Context: Immigration and co-production}

The findings from the seven policy interviews are analysed and discussed in this section.

Asylum seekers were generally considered to occupy a powerless legal position and this was closely associated with UK immigration legislation and policies. Public policy respondents were unanimous in confirming the limited power the Scottish Government had in influencing the legal status of asylum seekers, whilst having more flexibility in how their social and economic needs were met.

Co-production at the policy level was fatally compromised by asylum seekers' legal status as non-citizens because 'they are not formally meant to engage' (AP Strategic Manager). This was given weight by comments from the Government Agency respondent who expressed a professional ambivalence to participative co-production for asylum seekers, arguing that it was not always appropriate 
for them to be directly involved in decision making at a strategic level, either because they were not equipped or because these strategic issues (often involving an implicit assumption of citizenship and a commitment to broader social goals) were deemed inappropriate areas of discussion for asylum seekers:

Not at the strategic level... it really wouldn't be an appropriate forum for them anyway because to be fair we're not talking about operational issues, we're talking about business planning, forecasting for the future... (Government Agency)

In contrast, there was a widespread view among policy respondents that asylum seekers should be and were engaged in debates around the delivery of public services: ' . . they are still service users and there are still public duties around engagement there.' (CPP Respondent). However the respondents' views were divergent around the domain of asylum seeker co-production and whether co-production should extend beyond the consumer mode to the participative and enhanced forms. For example, while one respondent suggested that asylum seekers 'should be at the heart of planning' (SG Policy 1), another argued that the expectation of co-production during service planning was overly 'ambitious' (CPP Respondent).

Various respondents explained that, from the Scottish perspective, integration should start as soon as asylum seekers arrive in the country due to strong economic drivers and a commitment to maintaining a Scottish population of above five million.

... if people arrive in Glasgow, the first thing we try and do is help integrate them into the community for however long their stay is. So that's a different view from... Central Government. And that's caused some tensions in the past... (AP Strategic Manager)

Furthermore, the Scottish Government was keen to start the process of social integration as quickly as possible through opportunities for volunteering and education - such as English for Speakers of Other Languages courses. Such opportunities were considered to have a beneficial impact upon community integration and the economy: 'Community integration and the economic... you know when they move up they'll provide to the economy' (SG Policy 1).

The Scottish Government had little direct engagement with asylum seekers around services delivery, instead funding third sector organisations (TSOs) to provide services to asylum seekers and also to gather their views. The role of the Scottish Refugee Council, in particular, was described by policy respondents and PSO service managers alike as crucial to participative co-production, offering a platform through which asylum seekers could be consulted and their views fed back to strategic players. One such important platform funded by the Scottish Government was the Framework for Dialogue Groups (FFDGs) that were established to consult asylum seekers through TSOs. The FFDGs were described as providing 'a refugee/asylum seeker voice in the assessment of need 
process and the development of service bids' (Charity Manager). Indeed, the structure provided a means through which asylum seekers can raise any issues to do with services with those sitting in more strategic positions.

So what you've got now on the basic level is people who get together on a neighbourhood level and they can in some cases take issues up to service level locally or at a bigger level. And they can take issues up with government in various ways, both at the Scottish level and the Westminster level. (Charity Manager)

\section{RQ1: Can asylum seekers, as non-citizens, co-produce the public services they receive and, if so, how do they co-produce these services?}

Despite their marginalised status, this study found clear instances of asylum seeker co-production across the case study. Figure 3 below shows that the three modes of co-production explicated earlier were indeed taking place across the sub-units. The discussion that follows will consider the occurrence of the three types of co-production in detail.

\begin{tabular}{|ccccccc|}
\hline & CA & CB & AP & H.Org & DO & YPG \\
\hline Consumer co-production & $\mathrm{X}$ & $\mathrm{X}$ & $\mathrm{X}$ & $\mathrm{X}$ & $\mathrm{X}$ & $\mathrm{X}$ \\
Participative co-production & & $\mathrm{X}$ & & $\mathrm{X}$ & $\mathrm{X}$ & $\mathrm{X}$ \\
Enhanced co-production & & & & $\mathrm{X}$ & $\mathrm{X}$ & \\
& & & & & & \\
\hline
\end{tabular}

Figure 3. The existence of individual co-production across sub-units

During the service interaction, co-production was evidenced primarily as consumer co-production, confirming the fundamental assertions made in the services management literature: where there is a service encounter, consumer co-production occurs and, interestingly, this influences user satisfaction, service performance and outcomes (Normann, 1991; Gronroos, 2007; Glushko and Tabas, 2009). Church B, for example, aimed to offer responsive services which met asylum seeker need and filled gaps in provision:

... when the asylum seekers first came... they didn't have the infrastructure for them, so really what happened was they gravitated towards the Church as a place where they were looking for clothing, prams, shoes, sheets... and then they saw that they needed help with their English classes... so they set up English classes for them. (Church B Service Manager)

Similarly, the Accommodation Provider utilised consumer co-production, present through the service encounter, to promote service user satisfaction and service improvement. The nature of the Accommodation Provider's work meant 
that front-line project workers had direct and early service encounters with asylum seekers arriving in Glasgow. The observation highlighted that support and advice was provided on an individual basis with the project worker stepping beyond his remit of checking accommodation to ensure the well-being of individual asylum seekers, establishing their needs and also feeding information on to public services providers with different remits to allow them to respond to service needs.

Asylum seeker interviews also confirmed the existence of consumer coproduction with respondents broadly stating that they had input to services at the point of delivery. They typically associated this with the propensity of service providers to listen to their service needs and act upon them:

Yes, everybody used to be asked what they would like to do next week and people's opinions used to be asked and they used to ask what people want to do. (Asylum Seeker 3)

I get support and I'm listened to by all the organisations, like schools and GPs. The only organisation that doesn't listen is the Home Office. (Asylum Seeker 2)

The relationships observed reflected Normann's (1991) moment of truth. Such service encounters were invariably in services that had been previously designed by service professionals with little direct input from service users. Thus consumer co-production here effected the enactment of the service but had little impact on its design or creation. Other examples of consumer co-production included the Young Persons' Organisation which evidenced the existence of consumer co-production through the input young people had in deciding the format of the service encounter in partnership with the service providers facilitating the session. The observation also highlighted the trust that the young person had in the service manager of the YPG. The young people generally discussed the relationship with service providers as being on a personal level and, while the service manager described the relationships as friendships, she noted that there was a core element of professionalism as well.

During the group interview, the young asylum seekers spoke at length of the importance of developing relationships with social workers. The health of these varied between individuals, with some having positive reflections such as 'my social worker is good to me', and others saying 'I don't have relationship with my social worker'. The young people described this as a 'personal thing': 'For my friend, they can't stand their social worker... It depends on the individual but mine is ok.' The service manager from Church B also suggested that relationshipbuilding was an important element of the service, saying that dialogue was crucial to the provision of responsive services:

... it's making sure that you communicate with them; it's making sure that you consult them; it's making sure that you regard them as being on equal footing, and in fact that you're serving them... You're actually doing what they want. (Church B Service Manager) 
Forms of participative co-production were also found where service user views were used to improve existing public services. These examples of participative co-production took the focus of operational service planning and generally took place during the service encounter. Four sub-units evidenced participative coproduction (see Figure 3), through both consumer and citizen participation mechanisms: choice, evaluation and consultation were the most prominent mechanisms. Church A, Church B, the Young Person's Organisation and The Humanitarian Organisation each used choice to provide asylum seekers with some control over their service needs.

Church A offered various services to asylum seekers, including a craft session for women and an after-school drop-in session for families. Observing these sessions highlighted that such services were accessed as and when asylum seekers chose. Service users were also encouraged to decide which activities they would participate in during the craft sessions. Asylum seekers were not involved in the operational or strategic planning services at Church A: 'Not here, we don't specifically have asylum seekers and refugees helping to plan things out here' (Church A Service Manager). This was attributed to the informal structure of the services provision and was confirmed by the observations.

The service manager from the Young Person's Organisation also suggested that co-production at the strategic level was not feasible. Having participative co-production at the operational level and feeding views back to the strategic level was deemed more appropriate. Although young people had previously sat on the Board of the Partnership this was no longer the case, primarily due to funding issues, but also as the result of specific challenges related to the strategic nature of these needs. The service manager explained that the information being shared and discussed might be inappropriate for asylum seekers, who were not always equipped to contribute at this level. Furthermore, strategic players were not always welcoming or willing to listen to young asylum seekers.

... I think some things for a young person to hear first hand can be quite distressing... some young people's level of understanding, and the speed at which some things can take place as well can be quite frustrating.

There are some organisations that are very young person friendly and have an understanding of the value and importance of young people being there. Equally I think there are people who sit round tables and think 'what are these young people doing in here?' (YPG Service Manager)

Despite this, the service manager was of the view that the core aim of giving young people a voice was still achieved.

... unaccompanied young people's voices are still being heard through other routes and that's been fed into the Board when they've met, within papers and within other documents, within consultation papers and things like that... 
The majority of PSOs were also doing some form of 'more or less formal evaluation' to establish whether services were 'needs-led'. PSOs were generally willing to modify services in line with the service users' feedback, often proactively responding to suggestions.

But again it's regularly reviewed and evaluated so young people can tell us, 'I don't want this, I want less of this and I want more of this'. (Young Persons' Organisation Service Manager)

The adult literacy classes at the Development Organisation were evaluated every six to eight weeks. While the front-line tutor recognised that funders want 'value for money', he said that evaluation was also conducted to make improvements to the service: 'We don't do happy sheets that are filed away and never looked at again; we do read them and take things on board.' Other service managers also explained that while evaluation was linked to accountability to government funders, there was also a need to be accountable to the rest of the sector and also to promote service improvement.

... if we want to be challenging and we want to think of how we're doing things, and we want to continually be held accountable to... by the refugee community and by people who work in the sector to say, 'yeah, this is good, this is bad, improve, get better.' (Humanitarian Organisation Service Manager)

Overall, there was some general agreement among service providers that the citizen participation mechanisms afforded by participative co-production resulted in more personalised services that better met service users' needs. Consultation was a key tool utilised by PSOs either directly or, more typically, through the FFDG structures and was considered fundamental to service planning: 'What we're saying is you don't develop services for a client group without having clear ways of consulting with that client group' (Charity Service Manager).

Consultation was used in various formats by the Young Person's Organisation to strengthen the voice of the young people and ensure needs were being met. It was a core element of the group's activities, with various organisations using the group as a means of accessing the young people. The observation conducted as part of this research illustrated this. A social care organisation consulted the group about how they contribute to public service providers, asking also how they would like to contribute in the future. The service manager described some novel approaches being used, highlighting that consultation is not confined to a formal written method, but tailored to the group being consulted: 'We've had a talking wall, you know put stuff up and draw bricks on the wall and we've just put post-its up as well.'

Nevertheless, a conflicting argument was posed around not involving asylum seekers. This was not, however, related to an unwillingness to engage with asylum seekers on the behalf of professionals or service providers but rather the reluctance 
of asylum seekers. The most commonly espoused concern was related to the negative impact involvement might have upon a claim for asylum:

I could say that the Home Office could prevent me from saying something. (Asylum Seeker 8)

Asylum seekers are very wary of doing anything that will jeopardize their claim. (Accommodation Provider Strategic Manager)

Despite this, the asylum seekers who participated in this study were largely keen to speak up about public services, despite having some concerns that their views would not be listened to:

'Nothing would stop me voicing my opinion' (Asylum Seeker Group Interview).

'... when we started, I felt that what we're going to say about it is just going to be thrown in the bin. It's not important for people. But after that we felt that we were heard...' (Asylum Seeker 8).

Enhanced co-production was also found, but to a lesser extent. Enhanced coproduction is not situated in the realm of high-level policy-making or strategic planning, but rather is concerned with deep involvement in the operational design of public services. It is concerned either with service-user involvement in the fundamental co-design and co-creation of new forms of public services to meet needs or with co-production being used to achieve broader societal goals, such as social inclusion.

The analysis suggests that enhanced co-production exists on a continuum of service-user activeness with two clear opposing examples being found. The first was witnessed in the Development Organisation through the provision of adult literacy services. A core goal underpinning this service was the inclusion and integration of asylum seekers. The observation demonstrated the informal and fluid nature of the service which, although directed by the tutor, was shaped by the contributions of the service users throughout the process of service planning, delivery and evaluation. The service users also contributed to their individual learning plans, to tailor what they would learn, and then contributed again during the course of the class, through interactions with the tutor.

Another example of enhanced co-production was the provision of a clientled orientation service by the Humanitarian Organisation, which was planned and executed on an individual level. The aim of the service was to 'help asylum seekers with the integration process'. Here, the service user was more active than in the case of the Development Organisation.

Asylum seekers were viewed as experts in their own lives, with valuable knowledge and experiences (see von Hippel's, 1994, conception of 'sticky' information) and therefore in a position to make important service contributions which was fundamental to the provision of the service. The focus was on fostering asylum-seeker independence through support rather than dictating their needs. The caseworkers - typically volunteers who had been granted refugee status in the 
past and were therefore considered well-placed having experienced the hardships of the asylum process - worked on a one-to-one basis with asylum seekers. This created fertile ground for a relationship to develop, which in turn led to greater information sharing by both parties. Such an approach placed service users in a central role in the service innovation process as co-designers and co-creators, while the caseworker facilitated them through service interactions in uncovering and satisfying latent need:

We call it ... non-directional advocacy, so you can advocate on behalf of somebody... it's assisting someone who can't quite make their point, not going... into a meeting and saying "She needs this, she needs that." It is about that person saying I would like this service... (Humanitarian Organisation Service Manager)

However, channeling the knowledge and resources of service users can be challenging and depends upon continuous and equal dialogue between the service user and provider (Prahalad and Ramaswamy, 2000). The analysis of the Humanitarian Organisation's service suggested that allowing service users to shape their own services was dependent upon the development of a close but professional relationship of trust. The respondents from the Humanitarian Organisation discussed the importance of promoting trust within the service relationship; this was considered to be of particular importance given the vulnerability of the group. The volunteer discussed the process:

At our first meeting they don't tell you everything but as you give them another appointment, another appointment, another appointment they come out and they tell you. So by that time, you know exactly where you're going to refer them, what they are going through... Just give them time to get used to the idea and begin to trust you. (Humanitarian Organisation - front-line service worker)

Furthermore, the asylum seeker community was described as transient, particularly now with the New Asylum Seeker Model where decisions are taken within six weeks. Thus, there is less time for PSOs to set up and develop dialogue with service users.

\section{RQ2: What are the implications of co-production for social inclusion and as a potential route to citizenship?}

This research offers fertile ground through which to explore the conceptual framework of co-production. Their status as non-citizens firmly prevents asylum seekers' engagement at a policy-making level. However, they exist simultaneously as public service users and, as such, their involvement in the co-production of services is integral to public service production and can be integral to service design and co-creation on the frontline, as the previous section has explored.

The fact that co-production is integral to the process nature of services is critical to the debate. The analysis and discussion confirms the existence of co-production, suggesting that, as public service users, asylum seekers 
will always play an active role in the process of public service production through consumer co-production. The level of service-user activeness can be extended through participative or enhanced co-production. This depends ultimately upon: the policy direction towards social inclusion and the extended forms of co-production (i.e. participative and enhanced); public services managers' disposition towards co-production; and, perhaps most importantly, the willingness and ability of front-line staff to build and sustain relationships with service users. Each of these will now be considered in light of the empirical evidence.

The political context in Scotland and specifically the promotion of social inclusion, from both the government and PSOs, elevates co-production as part of the process of integration. The mode of co-production and the role played by asylum seekers in the public service delivery process was, in this study, linked to the policy direction towards social inclusion and co-production (i.e. participative and enhanced). The analysis of the policy interviews highlighted that the Scottish Government's policy on co-production firmly places service users at the centre of public service production. Similarly, the interviews defined integration as a core policy goal of the Scottish Government.

As discussed in previous sections, consumer co-production can extend, with public service users becoming more active through participative and enhanced modes. The evidence from the case study suggests that the PSO controls whether and how this basic form of co-production is extended. Indeed, there was a widespread view among policy respondents and service managers alike that asylum seekers should be and were engaged operationally around public services as service users (i.e. this was the view of Scottish Government respondents 1 and 2, Accommodation Provider Strategic Manager, Community Planning Partnership, the Humanitarian Organisation, the Young Person's Group, Church B). The difference in opinion came over whether co-production should be restricted to service delivery through the consumer mode or whether it be extended into service planning and design through participative and enhanced modes. In the case of Church A, for example, co-production was limited to the service encounter rather than falling into service planning. The Humanitarian Organisation, by comparison, promoted 'non-directional advocacy' and encouraged asylumseeker service users to take the lead in the planning and delivery of their own services through enhanced co-production.

Co-production was a core element of the effective management of public services on a day-to-day basis, but was dependent upon the extent to which public service managers and front-line staff realised and applied co-production. Public service managers' disposition towards co-production was shown to be critical to the extent to which co-production took place. Church B, for example, used both feedback and evaluation mechanisms to ensure that the services were meeting needs. However, the observation suggested that some forms of feedback 
and input into the service were tokenistic, with the service providers not acting on the direct wishes of the service users. The Development Organisation, by comparison, used participative co-production through evaluation, volunteering and choice, not only to improve services on the basis of need but also to provide service users with some control over the services they use.

The evidence suggests that co-production is also predicated upon the buy-in of front-line employees. On the ground, there was a strong impetus towards the integration of asylum seekers in Scotland and the service encounter was often used as a means of developing relationships with asylum seekers to promote integration. Data gathered from both Church A and Church B highlighted integration as an underpinning goal: Church A, for example, offered drop-in sessions, craft groups and English classes and the service manager described these as offering a 'social and safe environment' where asylum seekers can 'integrate and socially interact'. Service providers from the public and third sectors alike showed a divergence away from the core service task to focus on more social welfare type services that would help to integrate asylum seekers in the Scottish society. For example, the Project Worker from the Accommodation Provider offered support and advice on an individual basis where he could, going beyond the main objective of checking the accommodation to ensuring the well-being of asylum seekers.

Developing trust was important for each type of co-production. For consumer co-production, trust was crucial to building initial relationships with asylum seekers to ensure they had access to required services and their needs were satisfied as a result. The service encounter (the initial 'moment of truth') was used to build trust with asylum seekers, who were often framed as a vulnerable group who needed dedicated support. The work of the Accommodation Provider is a good example of this: building relationships with newly arrived asylum seekers was a key goal of the project worker, despite this being deemed a long, slow process:

... the project workers were getting told, probably more than they should have been with people who they'd built up trust, like if they had been victimised or raped or tortured' (Accommodation Provider Service Manager)

Asylum-seeker respondents also broadly agreed that trust was 'important' (Asylum Seeker 2). A trusting relationship was typically associated with the qualities espoused by service providers:

I can trust people if the people in this organisation are good people, like $X$ and $Y$ and people from other groups. (Asylum Seeker 8).

[The Charity] do listen but it depends on who you speak to. Some help and some don't help. Some are very difficult. (Asylum Seeker 5) 
In terms of participative co-production, various respondents expressed the need to provide genuine opportunities for asylum seekers to have their voices heard, rather than offering tokenistic forms of involvement. Church B's service manager talked about asylum seekers' 'right to participate' in order for them to have ownership over the services they are using:

You want them to own it, as being theirs... I mean otherwise you're just imposing things on people and you're not actually giving them the dignity of making their own decisions.

However, the observation of the craft group at Church B seemed contrary to the description provided by the service manager. Although there were opportunities for the participants to decide on the format of the group, these were sometimes relatively tokenistic. When, for example, the service manager asked whether the participants would mind if a lady joined the group with her young child, the participants did not object. Nevertheless, their responses seemed to be discounted by the service manager, who exercised ultimate control over the format of the session.

Building trust was also fundamental to enhanced co-production. A core aim of the orientation service offered by the Humanitarian Organisation, for instance, was to foster a one-to-one relationship based on trust in order to 'help them with the integration process.' (Humanitarian Organisation Service Manager).

Building trust was also perceived as a significant challenge for PSOs particularly given the marginalised nature of asylum seekers. Although service encounters are critical sites for integration, for certain groups such points of access do not exist. For example, the service manager from Church A recognised a challenge in accessing male asylum seekers who do not utilise the drop-in services provided. There was, as a result, no point of access to assist this group with their claims for asylum or their broader public service needs.

\section{Conclusions and implications}

The discussion has considered whether asylum seekers, as non-citizens, can coproduce the public services they receive and, if so, what forms co-production takes and what are the implications of this enactment for social inclusion and as a potential route to citizenship?

In this study, there was a strong impetus to integrate asylum seekers through the service relationship, although the various service providers examined chose to implement and manage different forms of co-production. Indeed, it was at the discretion of PSOs to move beyond consumer co-production to either participative or enhanced modes.

The case of asylum seekers makes it clear that citizenship status is not a necessary precursor to co-production and the services management literature has given this argument theoretical weight by positioning co-production as an 
intrinsic element of public service production, particularly during service delivery where the inseparability of production and consumption forms the crux of the service relationship (Johnston and Clark, 2008; Vargo and Lusch, 2008). In this context, the effective management of co-production becomes a core issue for public service providers. This is demonstrated clearly in this study, particularly through the efforts of front-line staff to build relationships and trust with asylum seekers through consumer co-production in order to meet needs and build responsive services.

The discussion has further shown a widespread view that asylum seekers should engage in the production of public services through participative co-production and specifically through consultation, choice and evaluation. Although respondents agreed that participative co-production was not appropriate during strategic policy making, it was important at the operational level. Here, the aim was to improve existing public services through the dayto-day contributions of asylum seekers using both consumer and participative mechanisms. Enhanced co-production was also demonstrated, although this was to a lesser extent. The two examples uncovered in the study suggested that enhanced co-production sits on a continuum of service-user activeness. The commonality between the opposing examples was their shared goal; using different approaches, both sought the deep involvement of asylum seekers in the operational design of services to achieve goals of social inclusion.

None of the modes of individual co-production discussed here provide, or are intended to provide, asylum seekers with legal citizenship status. What they offer is a route towards a partial and restricted form of 'citizenship in practice' (Lister, 2003). Co-production does not have a positive impact upon their case for asylum, nor does it permit those seeking asylum to contribute on a political or economic level. However, co-production promotes and facilitates integration through the involvement of asylum seekers at the operation level of public service production. In this sense, co-production arguably offers a route through which asylum seekers can act as citizens (Lister, 2003) - albeit in a reduced capacity - through their position in the welfare state as public service users. It is their role as co-producer which offers a community, typically identified by its marginalised and powerless attributes, a participatory role which promotes their inclusion in society.

\section{References}

Alford, J. (2009), Engaging public sector clients: from service-delivery to co-production, Basingstoke: Palgrave Macmillan.

Anon, (2001), 'Let Scotland sort out the asylum mess', The Glasgow Herald, 14 August.

Anon, (2005), 'Deal means asylum seeker raid continue', The Scotsman, 25 November.

Bloch, A. (2000), 'Refugee settlement in Britain: the impact of policy on participation', Journal of Ethnic and Migration Studies, 26, 1, 75-88.

Bovaird, T. (2007), 'Beyond engagement and participation - user and community coproduction of public services', Public Administration Review' 67, 846-860. 
Brandsen, T. and Pestoff, V. (2006), 'Co-production, the third sector and the delivery of public services', Public Management Review, 8, 4, 493-501.

Cemlyn, S. and Briskman, L. (2003), 'Asylum, children's rights and social work', Child and Family Social Work, 8, 163-178.

Choules, K. (2006), 'Globally privileged citizenship', Race, Ethnicity and Education, 9, 3, 275-293.

Glushko, R.J. and Tabas, L. (2009), 'Designing service systems by bridging the 'front stage' and 'back stage", Information System E-business Management, 7: 407-427.

Gronroos, C. (2007), Service management and marketing: customer management in service competition, 3rd ed., Chichester: John Wiley \& Sons.

Haikio, L. (2010), 'The diversity of citizenship and democracy in local management reform', Public Management Review, 12(3): 363-384.

Johnston, I. (2003), 'Work ban on asylum seekers condemned', Scotland on Sunday, 25 May.

Johnston, R. and Clark, G. (2008), Service Operations Management: Improving Service Delivery, Harlow: Prentice Hall.

Kristensson, P., Matthing, J. and Johansson, N. (2008), 'Key strategies for the successful involvement of customers in the co-creation of new technology-based services', International Journal of Service Industry Management, 19, 4, 474-491.

Lewis, M. (2006), Warm welcome? Understanding public attitudes to asylum seekers in Scotland, London: Institute for Public Policy Research.

Lister, R. (2003), Citizenship: feminist perspectives, 2nd edition, Basingstoke: Palgrave Macmillan.

Normann, R. (1991), Service management: strategy and leadership in service business, 2nd ed., West Sussex: John Wiley and Sons.

Ordanini, A. and Pasini, P. (2008), 'Service co-production and value co-creation: the case for a service-orientated architecture (SOA)', European Management Journal, 26, 289-297.

Osborne, S.P. and Strokosch, K. (2013), 'It takes Two to Tango? Understanding the Coproduction of Public Services by Integrating the Services Management and Public Administration Perspectives', British Journal of Management, 24, S31-S47.

Ostrom, E. (1972), 'Metropolitan Reform: Propositions Derived from two traditions', Social Science Quarterly, 53, 474-493

Parks, R.B., Baker, P.C., Kiser, L., Oakerson, R., Ostrom, E., Ostrom, V., Percy, S.L., Vandivort, M.B., Whitaker, G.P. and Wilson, R. (1981), 'Consumers as co-producers of public services: some economic and institutional considerations', Policy Studies Journal, 9, 7, 1001-1011.

Prahalad, C.K. and Ramaswamy, V. (2000), 'Co-opting customer competence', Harvard Business Review, January/February, 79-87.

Sales, R. (2002), 'The deserving and undeserving? Refugees, asylum seekers and welfare in Britain', Critical Social Policy, 22, 456-478.

Sim, D. and Bowes, A. (2007), 'Asylum Seekers in Scotland: The Accommodation of Diversity', Social Policy \& Administration (41, 7) pp. 729-746.

Vargo, S.L. and Lusch, R.F. (2008), 'Service-dominant logic: Continuing the evolution', Journey of the Academy of Marketing Science, 36, 1-10.

von Hippel, E. (1994), 'Sticky information and the locus of problem solving: implications for innovation', Management Science, 40(4): 429-439.

Williams, L. (2006), 'Social networks of refuges in the United Kingdom: Tradition, tactics and new community spaces', Journal of Ethnic and Migration Studies, 32(5): 865-879.

Wren, K. (2007), 'Supporting asylum seekers and refugees in Glasgow: the role of multi-agency networks', Journal of Refugee Studies, 20(3): 391-413. 